\title{
Possibility to Establish Chicken Stem Cell from Non-germline Tissue; Detection of Colony-forming Cells after Chicken Fibroblast Culture and Subsequent Stem Cell Characterization
}

\author{
Jung Kyu Choi ${ }^{1, \text { a }}$, Ji Yeon $\mathrm{Ahn}^{2}$, a Jong IL $\mathrm{Ahn}^{3}$, Jae Hee Lee ${ }^{3}$, Sang Hyun Park ${ }^{4}$, Jong Heum Park ${ }^{5}$, \\ Seung Tae Lee ${ }^{6}$, Jae Yong Han ${ }^{1,3,4}$, Yong Sang Song ${ }^{2,7}$ and Jeong Mook Lim ${ }^{1,2,3}$ \\ ${ }^{1}$ Department of Agricultural Biotechnology, Seoul National University, Seoul 151-921, Korea \\ ${ }^{2}$ Cancer Research Institute, College of Medicine, Seoul National University, Seoul 110-799, Korea \\ ${ }^{3}$ Stem Cell and Bioevaluation, WCU Biomodulation Program, Seoul National University, Seoul 151-742, Korea \\ ${ }^{4}$ Avicore Biotechnology Institute, Hanlim Human Tower \#707, Geumjeong-Dong 1-40, Gyeonggi-Do 435-050, Korea \\ ${ }^{5}$ Radiation Research Division for Biotechnology, Korea Atomic Energy Research Institute, Jeongeup 580-185, Korea \\ ${ }^{6}$ Department of Animal Biotechnology, Kangwon National University, Chuncheon 200-701, Korea \\ ${ }^{7}$ Department of Obstetrics and Gynecology, College of Medicine, Seoul National University, Seoul, 110-744 Korea
}

This study was conducted to evaluate whether culture of chicken fibroblasts could induce cell aggregation leading to embryonic stem cell (ESC)-like, colony-formation. Gradual increase in expression of leukemia inhibitory factor (LIF) gene were detected as retrieval age of chicken embryonic fibroblasts (CEFs) was increased from 5- to 8day-old, which accompanied increase in cell proliferation after culture in LIF-free medium. Colony-like cell aggregation was detected after culture of the 8-day-old fibroblasts, while the exposure to $0.5,1$ or $2 \mathrm{mM}$ glutathione did not increase the cell aggregation. The cell aggregates were positive for periodic acid Schiff solution, and the antibodies of anti-stage specific embryonic antigen (SSEA)-1 and anti-SSEA-3. However, they were negative for alkaline phosphatase and anti- SSEA-4 antibody. Expression of chicken Vasa homolog did not detect in the aggregated CEFs. Continuous culture of the aggregates in LIF- and CEF monolayer-free condition resulted the formation of embryoid bodies possessing the cells being positive for three germ layer makers (Nestin, S-100, smooth muscle actin, desmin, alpha-fetoprotein and Troma-1). In conclusion, our results demonstrate cell aggregates having ESC-like activity can be derived from the culture of chicken fibroblasts on CEF monolayer, which strongly supports the possibility on deriving chicken stem cells from non-germline tissue.

Key words: chicken, colony formation, embryonic fibroblasts, leukemia inhibitory factor (LIF), stemness

J. Poult. Sci., 49: 196-204, 2012

\section{Introduction}

Avian germ cell has unique trait on gonadal migration through the circulatory system (Van de Lavoir et al., 2006), which can induce germline transmission by the transfer of avian stem cells into the circulatory blood of developing embryos. From this reason, stem cells of birds have a great value for producing transgenic animals (Petitte et al., 2004), as well as for establishing human disease models (Reynes et al., 1992). To date, germline chimeras have successfully

Received: September 15, 2010, Accepted: January 27, 2012

Released Online Advance Publication: March 25, 2012

${ }^{\mathrm{a}} \mathrm{Co}$-first author of this manuscript

Correspondence: Dr. JM Lim, Laboratory of Stem Cell and Bioevaluation, WCU Biomodulation Program, Seoul National University, Korea.

(E-mail: limjm@snu.ac.kr) been derived from the transfer of primordial germ cells (PGCs), PGC-derived embryonic germ (EG) cells and germline stem cells (Park et al., 2003; Jung et al., 2007). Transgenic aves were recently developed from genetically modified PGCs in quails (Shin et al., 2008) and chicken (Kim et al., 2010). However, the methods to establish and to maintain avian stem cells are very much unique and sophisticate in domestic fowls (Horiuchi et al., 2004) compared with those in mammalian species, which needs more efforts to be optimized.

Recently, a technique to derive induced pluripotent cells by genetic manipulation of several stemness-related genes was developed (Takahashi and Yamanaka, 2006; Okita et al., 2007). We further reported that ESC-like cells can be derived from non-germline cells by utilizing cell-to-cell interaction without genetic manipulation in a model animal (Gong 
et al., 2010). In this study, we attempted to establish chicken stem cells from the culture of non-germline, chicken fibroblasts retrieved from developing embryos under the similar, gene manipulation-free condition reported previously. We subsequently evaluated whether the derived, colony-forming cell had stem cell activity.

\section{Materials and Methods}

\section{Animals}

Fertilized eggs of White Leghorn (WL) that were maintained at the University Animal Farm, Seoul National University, Korea, were brought in the laboratory. Five- to 8day-old White Leghorn (WL) embryos after incubating them in the laboratory were employed for the retrieval of chicken fibroblasts. All procedures for animal management, reproduction, and surgery were performed in accordance with the standard protocols of Seoul National University, and institutional animal care and use committee has approved experimental procedure in this study.

\section{Experimental Design}

In experiment 1 , de novo synthesis of chicken leukemia inhibitory factor (LIF) in CEFs retrieved from 5- to 8-day old embryos was compared. Proliferation of the fibroblasts retrieved from the same ages was measured with a colorimetric cell counting kit (CCK) -8 (Dojindo Laboratories, Kumamoto, Japan) assay and the duration to reach into $70 \%$ confluency was also monitored. In experiment 2 , the fibroblasts retrieved from 8-day- old embryos were cultured in LIF (Chemicon, Temecula, CA, USA)-containing medium Dulbecco's Modified Eagle's Medium (DMEM) supplemented with $10 \%(\mathrm{v} / \mathrm{v})$ fetal bovine serum (FBS) and $1 \%$ $(\mathrm{v} / \mathrm{v})$ penicillin-streptomycin], to which $0,0.5,1$ or $2 \mathrm{mM}$ glutathione (Sigma-Aldrich, Tokyo, Japan) was supplemented. Colony-like cell aggregates formed during primary culture were characterized with novel stem cell markers and embryoid body formation in the absence of CEF monolayer and LIF was subsequently evaluated.

\section{Retrieval of CEFs and Counting Cell Number}

CEFs were isolated from skin of 5- to 8-day-old WL eggs after the head, arms, legs, tail and other internal organs were removed. After chopping embryonic tissue by scissors, the collected tissues were incubated for 10 minutes at $37^{\circ} \mathrm{C}, 5 \%$ $\mathrm{CO}_{2}$ in air atmosphere with $0.04 \%$ trypsin/EDTA solution. The cell suspension was centrifuged twice at $400 \mathrm{~g}$ for 4 minutes and centrifuged again with filtering through $40-\mu \mathrm{m}$ nylon cell strainer (BD Falcon, Franklin Lakes, NJ, USA). Total cell number of CEFs was then counted using a hematocytometer.

\section{Culture of CEFs, and Monitoring of Cell Viability and Cell Aggregate Formation}

Five-thousands CEFs retrieved from the embryos of different ages were seeded into one well of a 96-well dish containing $0.2 \mathrm{ml}$ of Dulbecco's Modified Eagle's Medium (DMEM; GIBCO-Invitrogen, Carlsbad, CA, USA) supplemented with $10 \%$ (v/v) fetal bovine serum (FBS; Hyclone Laboratories, Logan, UT, USA) and $1 \%(\mathrm{v} / \mathrm{v})$ penicillinstreptomycin. The cells were incubated for 24 hours at $37^{\circ} \mathrm{C}$,
$5 \% \mathrm{CO}_{2}$ in air atmosphere and then treated with $\mathrm{CCK}-8$ reagent (Dojindo Laboratories, Kumamoto, Japan) for 2 hours before the end of the culture. The viability of CEFs was measured at $450 \mathrm{~nm}$ using Bio-Rad microplate reader Model-550 (Bio-Rad, Hercules, CA, USA). Concomitantly, CEFs retrieved from different ages were cultured in one well of a 4-well multi dish and their proliferation to reach $70 \%$ confluency was evaluated during primary culture for 6 days under an inverted microscope (Eclipse TE-3000; Nikon, Tokyo, Japan).

Based on preliminary results, CEFs retrieved from 8-dayold embryos were cultured in LIF-containing DMEM supplemented with $10 \%(\mathrm{v} / \mathrm{v})$ fetal bovine serum (FBS) and antibiotics, to which $0,0.5,1$ or $2 \mathrm{mM}$ glutathione was added. The number and diameter of cell aggregates were counted by an inverted microscope (Eclipse TE-3000; Nikon, Tokyo, Japan) equipped with Axiovision AC (Carl Zeiss, Oberkochen, Germany).

\section{Analysis of the Relative mRNA levels of LIF}

One hundred thousand CEFs were transferred to a $1.5-\mathrm{m} l$ tube containing RNAlater ${ }^{\circledR}$ (Ambion ${ }^{\circledR}$, Austin, TX, USA) immediately after retrieval from 5-, 6-, 7- or 8-day-old embryos and stored at $-75^{\circ} \mathrm{C}$ until analysis. Total mRNA was extracted from samples using RNeasy ${ }^{\circledR}$ PlusMini Kit (Qiagen, Valencia, CA, USA). The relative Lif mRNA levels in CEFs retrieved were analyzed by real-time PCR (Applied Biosystems 7300 Real-time PCR system, Foster City, CA, USA). The mRNAs were reverse-transcribed into cDNAs using a Super ScriptTM III First-Strand (Invitrogen, Carslbad, CA, USA). Equal quantities of normalized cDNA were used as template in PCR reactions with chLIF-specific primers as follows: forward (5'-TCCTCAACGCCTCACTGG-3') and reverse $\left(5^{\prime}\right.$-GCCCTGCTGCTTCTTCTT- $\left.3^{\prime}\right)$. The priers used for amplification of GAPDH were as follows: forward $\left(5^{\prime}-\right.$ ACCACTGTCCATGCCATCAC-3') and reverse (5'-GACGCTGGGATGATGTTCTG-3'). Real-time PCR was performed with a SYBR ${ }^{\circledR}$ Green qPCR kit (Finnzymes, Espoo, Finland) run for 35 cycles of $95^{\circ} \mathrm{C}$ for 30 seconds, $60^{\circ} \mathrm{C}$ for 45 seconds, and $72^{\circ} \mathrm{C}$ for 30 seconds. Data on melting curve were collected to check the PCR specificity. The GAPDH primer was included in every group and the mRNA level of each sample for each gene was normalized to that of the 5 GAPDH mRNA. Relative mRNA level was presented as $2^{-\Delta \Delta \mathrm{Ct}}$, where $\mathrm{Ct}=$ threshold cycle for target amplification, $\Delta \mathrm{Ct}=\mathrm{Cttarget}$ gene (LIF) Ctinternal reference (GAPDH), and $\Delta \Delta \mathrm{Ct}=\Delta \mathrm{Ctsample} \mathrm{(each} \mathrm{groups)-} \Delta$ Ctcalibrator (5 daysold).

\section{Marker Assay}

Both CEFs and mouse embryonic stem cells (ESCs) of E14 strain as a control group were washed twice in $\mathrm{Ca}^{2+}$. and $\mathrm{Mg}^{2+}$-containing PBS and were subsequently fixed in $4 \%$ formaldehyde at room temperature for 10 minutes. In the case of alkaline phosphatase (AP) staining, cell aggregates reacted were visualized with fast red TR-naphthol (SigmaAldrich, St Louis, MO, USA) AS-MX phosphate (SigmaAldrich, St Louis, MO, USA). For periodic acid Schiff (PAS) staining, the cell aggregates and ESCs were immersed 
in periodic acid solution (Sigma-Aldrich, cat. no. 395b, Egham, UK) for $5 \mathrm{~min}$ and were subsequently treated in Schiff solution (Sigma-Aldrich, Egham, UK) for $10 \mathrm{~min}$. In the case of anti-SSEA-1, anti-SSEA-3 and anti-SSEA- 4 staining, each of monoclonal antibodies was obtained from the Developmental Studies Hybridoma Bank (Iowa City, IA, USA). Antibody localization was performed by using the DakoCytomation kit (DakoCytomation, Carpinteria, CA, USA), and the localized cells were observed under an inverted microscope (TE2000-U; Nikon, Tokyo, Japan). Cell aggregates, the adult testes of WL and CEFs retrieved from 8-day-old WL embryos were provided for RT-PCR and mRNA of each sample was isolated using a RNeasy ${ }^{\circledR}$ Plus Mini Kit (Qiagen, S.A., Courtaboeuf, France). The mRNA extracted were reverse-transcribed into cDNAs using a Super ScriptTM III First-Strand (Invitrogen, Carslbad, CA, USA) and the following primer pairs were used: for chicken vasa homologue (Cvh), forward 5' -GCTCGATATGGGTTTTGGAT-3' and reverse 5' -TTCTCTTGGGTTCCATTCTG C$3^{\prime}$. Each PCR product was analyzed on $1 \%$ of agarose gel and visualized with ethidium bromide.

In vitro-differentiation of Cell Aggregates in LIF-free Medium

To examine whether the cell aggregates could form embryoid bodies (EBs), the harvested aggregates were resuspended in culture media without LIF and placed in a nonadhesive bacterial Petri dish (SPL Lifescience, Pochunsi, Korea). The EBs formed 4 days after the culture in LIFfree medium in the absence of CEF monolayer were subsequently provided for immunocytochemical analysis using three germ layer-specific markers: Nestin (Santa Cruz Biotechnology, Delaware, CA, USA) and S-100 (Abcam, Cambridge Science Park, Cambridge, UK) for the ectodermal layer; muscle actin (Abcam, Cambridge Science Park, Cambridge, UK) and desmin (Santa Cruz Biotechnology, Delaware, CA, USA) for the mesodermal layer; and $\alpha$ fetoprotein (DAKO, Carpinteria, CA, USA) and Troma-1 (Hybridoma Bank, Iowa City, IA, USA) for endodermal cells. Localization of the antibodies was performed by using the DakoCytomation kit (DakoCytomation, Carpinteria, CA, USA).

\section{Statistical Analysis}

A generalized linear model (PROC-GLM) in a Statistical Analysis System (SAS) program was employed for statistical analysis of numerical data. One-way ANOVA followed by the least-square method was conducted when the parameter had model effect. Significant differences among treatments were determined where the $\mathrm{p}$ value was less than 0.05 .

\section{Results}

\section{Experiment 1: Culture of CEFs and Derivation of Cell Ag- gregates}

As shown in Table 1, more CEFs were retrieved from 8day-old embryos than from 5- to 7- day old embryos, which accompanied with increased growth rate $(0.75$ vs. 0.58 to 0.66 ) and fast reaching into $70 \%$ confluency ( 1 day vs. 4 to 6 days). In supplementary experiment employing 8-day-old embryos, we counted the number of cells that were positive for SSEA-1 immediately after the retrieval of fibroblasts. Average number of SSEA-1 positive cells was $1,023 \pm 446$, which were mingled into 1.58 to $1.83 \times 10^{7}$ fibroblasts immediately retrieved. So the percentile of these SSEA-1 positive cells in original cell fraction was within the range of 0.003 to $0.009 \%$. Vigorous proliferation of fibroblasts was notable during primary culture up to for 6 days (Fig. 1). Expression of Lif were gradually increased, which resulted the highest expression in the CEFs retrieved from 8-day-old embryos than the CEFs retrieved from the embryos of other ages (Fig. 2).

Colony-like, cell aggregation was detected in several batches of culture using the 8-day-old CEFs with DMEMbased medium. The shape of cell aggregates varied, but they were composed of uniformed cells (Fig. 3). As shown in Table 2, size and frequency of cell aggregates was within the ranges of 47 to $203 \mu \mathrm{m}$ and 5.3 times/replications, respectively. Total 64 aggregates were derived from 12 replicates, which consisted of 17 aggregates from $0 \mathrm{mM}, 12$ aggregates from $0.5 \mathrm{mM}$, 19 aggregates from $1 \mathrm{mM}$ and 16 aggregates from $2 \mathrm{mM}$ GSH addition. There was no significant difference in the frequency of cell aggregate derivation among different GSH concentrations.

\section{Experiment 2: Characterization of Cell Aggregates}

As shown in Fig. 4, cell aggregates derived from the cul-

Table 1. Growth of white leghorn chicken embryonic fibroblasts (CEFs) retrieved from developing embryos

\begin{tabular}{ccccc}
\hline \hline $\begin{array}{c}\text { Ages of CEF donor } \\
\text { (days after laying) }\end{array}$ & $\begin{array}{c}\text { No. of embryos } \\
\text { collected }\end{array}$ & $\begin{array}{c}\text { No. of CEFs retrieved } \\
\left(\times 10^{7}, \text { mean } \pm \text { SD }\right)\end{array}$ & $\begin{array}{c}\text { Growth rate }^{\mathrm{a}} \\
(\text { mean } \pm \text { SD })\end{array}$ & $\begin{array}{c}\text { Days of reaching } \\
70 \% \text { confluency }\end{array}$ \\
\hline 5 & 5 & $1.10 \pm 0.15^{\mathrm{b}}$ & $0.58 \pm 0.01^{\mathrm{b}}$ & $>6$ days \\
6 & 5 & $1.41 \pm 0.37^{\mathrm{b}}$ & $0.63 \pm 0.04^{\mathrm{c}}$ & 6 days \\
7 & 5 & $2.00 \pm 0.11^{\mathrm{c}}$ & $0.66 \pm 0.03^{\mathrm{cd}}$ & 4 days \\
8 & 5 & $2.18 \pm 0.31^{\mathrm{c}}$ & $0.75 \pm 0.02^{\mathrm{e}}$ & 1 days \\
\hline
\end{tabular}

CEFs were cultured in Dulbecco's modified Eagle's medium supplemented with 10\% (v/v) fetal bovine serum and antibiotics.

a $5 \times 10^{3}$ CEFs were seeded into a 96-well culture plate and their growth rate was monitored by colorimetric cell counting kit 24 hours after seeding.

${ }^{\mathrm{b}-\mathrm{e}}$ Different superscripts within a column were significantly different, $p<0.05$. 

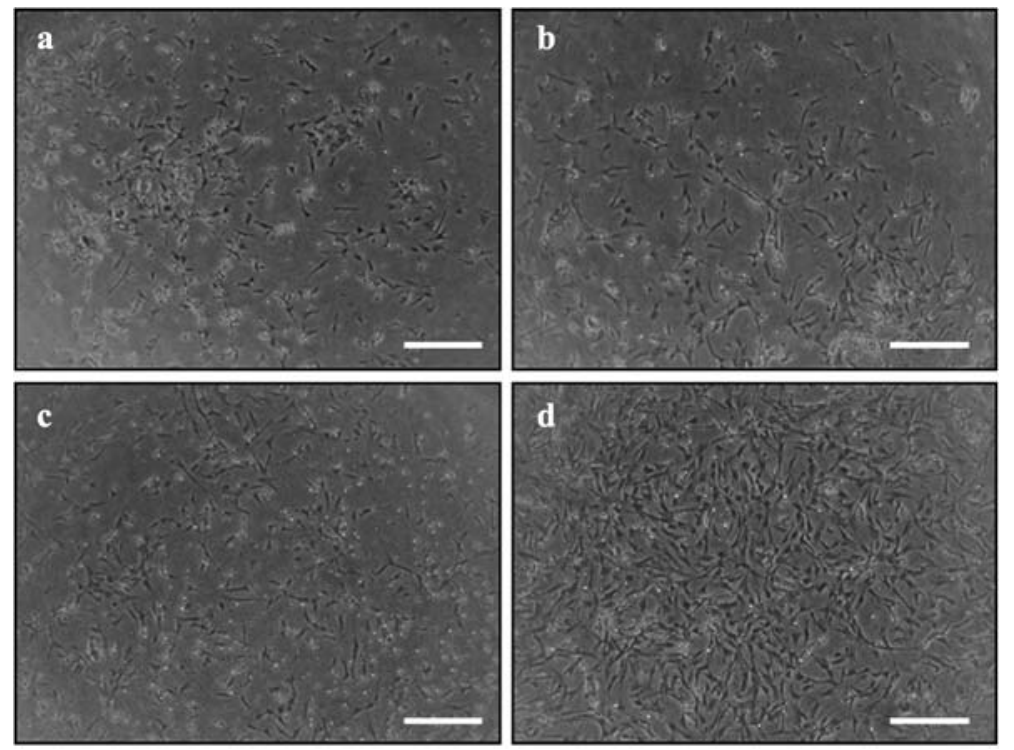

Fig. 1. Proliferation of white leghorn chicken embryonic fibroblasts (CEFs) retrieved from developing embryos of 5-day-old (a), 6day-old (b), 7-day-old (c) or 8-day-old (d). The collected CEFs of $1 \times$ $10^{5}$ were cultured for 24 hours in Dulbeco's modified Eagle's medium (DMEM) supplemented with fetal bovine serum and antibiotics, and their proliferation after being cultured in one well of a 4-well culture dish was monitored under an inverted microscope. More proliferation was detected in CEFs collected from 8-day-old chick embryos than 5- to 8day-old chick embryos. Scale bar $=50 \mu \mathrm{m}$.

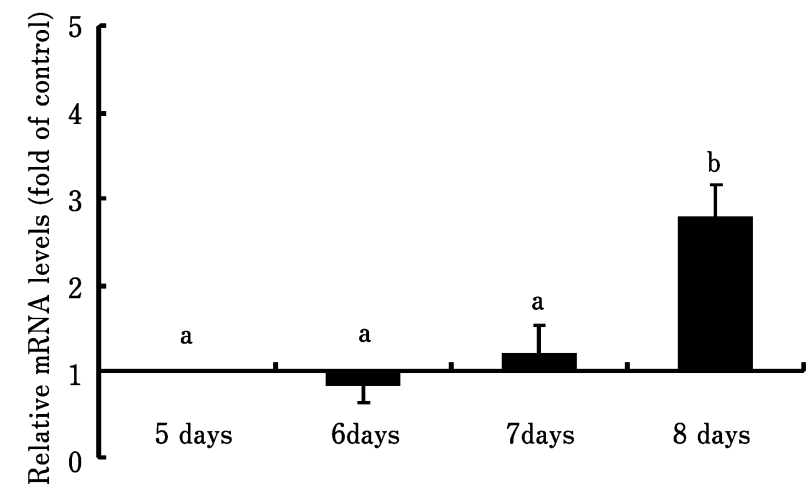

Fig. 2. Relative level of chicken leukemia inhibitory factor (chLIF) gene expression in chicken embryonic fibroblasts (CEFs) collected from developing embryos of different ages. CEFs of $1 \times 10^{5}$ were retrieved from white leghorn embryos of 5-day-old, 6-day-old, 7-day-old, or 8day-old and chLIF mRNA expression was quantified by real-time PCR. All levels measured were normalized to the level of GAPDH mRNA. More expression of chLIF gene was detected in CEFs collected from 8-day-old embryos than in CEFs collected from 5-7-day-old embryos. Model effect of treatment was less than 0.0001 and different superscripts $(\mathrm{a}$ and $\mathrm{b})$ indicate significant differences between treatments, $p<0.05$. ture of colony-like cell aggregates were positive for PAS, and ant-SSEA-1 and anti-SSEA-3 antibodies, while they were negative for AP, anti-SSEA-4 antibody. Cvh expression was not detected in both cell aggregates and CEFs, while testicular tissue of the positive control showed strong $C v h$ expression. As shown in Fig. 5, the cell aggregates were transformed into EB-like cell mass by in vitro-culture in LIF-free medium. The EB-like cell mass consisted of the cells being stained with three germ layer marker S-100, Nestin, smooth muscle actin, desmin, $\alpha$-fetoprotein and Troma- 1 .

\section{Discussion}

Through this study, we found the fact that CEFs derived from developing chicken embryos expressed LIF and subsequently that the culture of CEFs resulted colony-like cell aggregates. The cell aggregates formed during primary culture expressed several stemness-related markers, while there was no expression of germ cell-specific $C v h$ genes. The aggregates had a potency to transform into EBs in LIF-free medium, which consisted of three germinal layer-derived cells in LIF-free medium.

Chicken germline cells acquiring pluripotent activity have been employed for various researches on transgenesis and germline chimera production (Wang et al., 2006). Their unique nature to germ cell migration through circulatory system in chicken is able to simply induce germline transmission by the transfer of pluripotent cells into blood stream of 

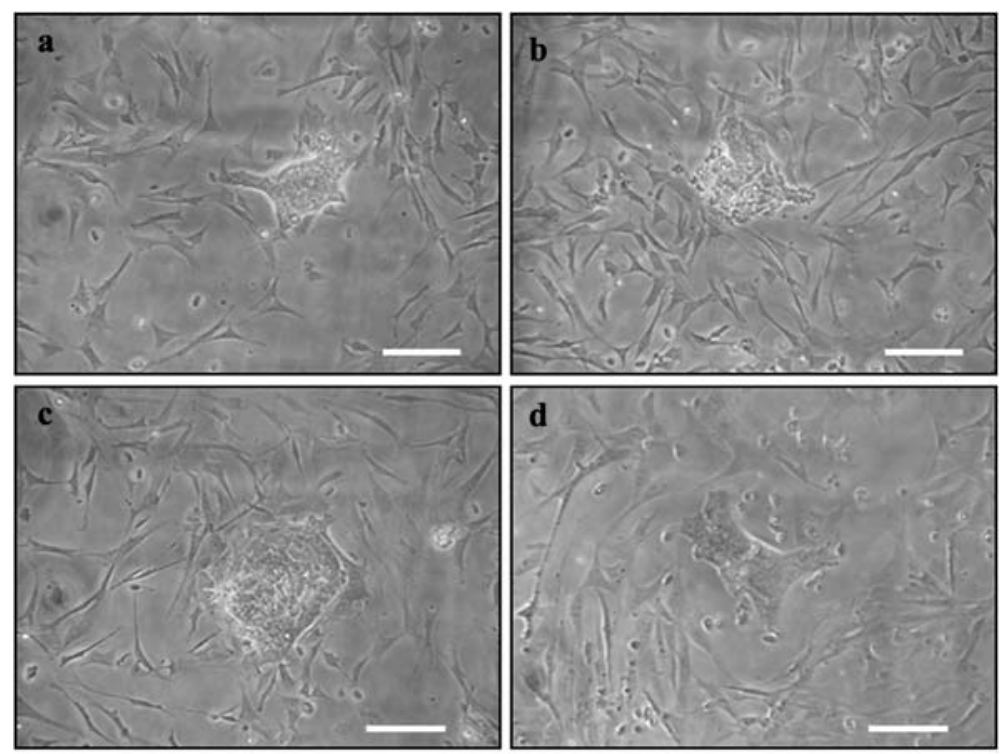

Fig. 3. Colony-like, cell aggregation of chicken embryonic fibroblasts (CEFs) during primary (passage 0) culture. CEFs were collected from 8-day-old white leghorn embryos and were subsequently cultured for 5 days in Dulbecco's modified Eagle's medium (DMEM) supplemented with fetal bovine serum and antibiotics, to which 0 (a), 0.5 (b), 1 (c) or 2 (d) mM glutathione (GSH) was added. Regardless of glutathione concentration, colony-forming cells were observed, while GSH concentration influenced size and morphology of aggregated cells. Scale bar $=50 \mu \mathrm{m}$.

developing embryos, which yield a prior feasibility in biotechnological industries compared with the mammals. To date, there has been an achievement in producing germline chimeras by germ cell transfer into blood stream (Naito et al., 1994; Park et al., 2003; Kim et al., 2005; Yamamoto et al., 2007), and in generating interspecies (Kang et al., 2008) and transgenic (Ono et al., 1998; Van de Lavoir et al., 2006) chimeras. However, there are difficulties in germ cell retrieval from developing embryos and in culturing of germ cells without losing their activity in vitro. Derivation of stem cells from chicken non-embryonic, somatic tissue may be one of the alternatives for overcoming such difficulties in avian biotechnology.

Fibroblasts are present in connective tissue differentiated from mesenchymal tissue of mesodermal origin. Various cells mediating structural and functional roles, such as collagen network formation and wound healing, are derived from mesenchymal tissue, leading to cell differentiation and transformation (Moulin et al., 1999; Kues et al., 2000). We therefore presumed that fibroblasts or fibroblast-derived cells in developing embryos might to maintain their pluripotent activity. In this study, we found the cells inducing cell aggregation in embryonic fibroblasts. These data demonstrate that CEFs may be employed as the supplier of pluripotent or ESC-like stem cells in addition to being employed as the supplier of monolayer-forming cells. Detection of Lif expression and reactivity to several stemness-related markers may further support our finding. Probably the cells having aggregation activity have a potency to induce multilineage differentiation, while these colony-forming cells could not successfully be maintained under our designated culture system. Further optimization of cell culture was definitely required for establishing cell line with complete cell characterization.

Nevertheless of finding colony-forming cells by culturing of fibroblasts, it is not clear which cell in fibroblast fraction is the origin of colony-forming cell. One possibility is that fibroblasts in developing embryos of certain ages can transform into the cells having aggregation activity in a specific culture environment. The expression of Lif in CEFs may support self-transformation of fibroblasts into colony-forming cells. Otherwise, there may be progenitor cells of colony-forming cells that were mixed in CEFs. Our supplementary results showing the presence of SSEA-1 positive cells supports this possibility. At this point, however, it is not clear whether these SSEA-1 positive cells are fibroblasts or not; mingled cells in the fibroblast fraction or the cells that are able to subsequently transform into the colony-forming cells during primary culture in vitro. In any case, cell-to-cell interaction with other cells consisting in fibroblast fraction may be important factor for establishing the cell aggregates.

In conclusion, there is a limitation to finally conclude on the feasibility of chicken fibroblasts as the source of stem cells based on the data obtained in this study. However, we 
Table 2. Number and size of colony-like cell aggregations derived from chicken embryonic fibroblasts (CEFs) in cultured medium supplemented with 0 to $2 \mathrm{mM}$ glutathione (GSH)

\begin{tabular}{|c|c|c|c|}
\hline Trials & Conc. of GSH (mM) & $\begin{array}{l}\text { No. of aggregated } \\
\text { cells formed }\end{array}$ & Size of cell aggregates $(\mu \mathrm{M})^{\mathrm{b}, \mathrm{c}}$ \\
\hline \multirow{4}{*}{1} & 0 & 1 & 69 \\
\hline & 0.5 & 2 & 132,81 \\
\hline & 1 & 1 & 98 \\
\hline & 2 & 2 & 172,102 \\
\hline \multirow{4}{*}{2} & 0 & 2 & 71,66 \\
\hline & 0.5 & 1 & 122 \\
\hline & 1 & 2 & 91,91 \\
\hline & 2 & 1 & 136 \\
\hline \multirow{4}{*}{3} & 0 & 3 & $84,84,95$ \\
\hline & 0.5 & 1 & 161 \\
\hline & 1 & 3 & $109,93,178$ \\
\hline & 2 & 3 & $50,140,89$ \\
\hline \multirow{4}{*}{4} & 0 & 2 & 123,130 \\
\hline & 0.5 & 1 & 84 \\
\hline & 1 & 1 & 191 \\
\hline & 2 & 2 & 156,113 \\
\hline \multirow{4}{*}{5} & 0 & 2 & 203,69 \\
\hline & 0.5 & 1 & 61,70 \\
\hline & 1 & 4 & $42,103,79,78$ \\
\hline & 2 & 2 & 65,72 \\
\hline \multirow{4}{*}{6} & 0 & 0 & - \\
\hline & 0.5 & 1 & 47 \\
\hline & 1 & 1 & 90 \\
\hline & 2 & 1 & 110 \\
\hline \multirow{4}{*}{7} & 0 & 0 & - \\
\hline & 0.5 & 0 & - \\
\hline & 1 & 0 & - \\
\hline & 2 & 0 & - \\
\hline \multirow{4}{*}{8} & 0 & 0 & - \\
\hline & 0.5 & 0 & - \\
\hline & 1 & 0 & - \\
\hline & 2 & 0 & - \\
\hline \multirow{4}{*}{9} & 0 & 4 & $108,61,64,98$ \\
\hline & 0.5 & 3 & $104,63,98$ \\
\hline & 1 & 4 & $80,58,102,69$ \\
\hline & 2 & 4 & $158,104,67,157$ \\
\hline \multirow{4}{*}{10} & 0 & 0 & - \\
\hline & 0.5 & 0 & - \\
\hline & 1 & 0 & - \\
\hline & 2 & 0 & - \\
\hline \multirow{4}{*}{11} & 0 & 0 & - \\
\hline & 0.5 & 0 & - \\
\hline & 1 & 0 & - \\
\hline & 2 & 0 & - \\
\hline \multirow{4}{*}{12} & 0 & 3 & $54,78,76$ \\
\hline & 0.5 & 2 & 74,114 \\
\hline & 1 & 3 & $90,84,99$ \\
\hline & 2 & 1 & 171 \\
\hline Total & $\begin{array}{l}0-2 \mathrm{mM} \text { in } 12 \\
\text { replicates }\end{array}$ & $\begin{array}{c}64 \text { aggregates } \\
(5.3 \pm 0.1 / \text { replicate })\end{array}$ & $98.5 \pm 36.4 \mu \mathrm{m}$ \\
\hline
\end{tabular}

Chicken embryonic fibroblasts CEFs collected from 8-day-old white leghorn embryos were pro-

vided.

${ }^{\mathrm{b}}$ Number of aggregated cells and their sizes were monitored on day 2 of primary culture.

${ }^{\mathrm{c}}$ Axiovision AC was employed for measuring cell aggregates. 

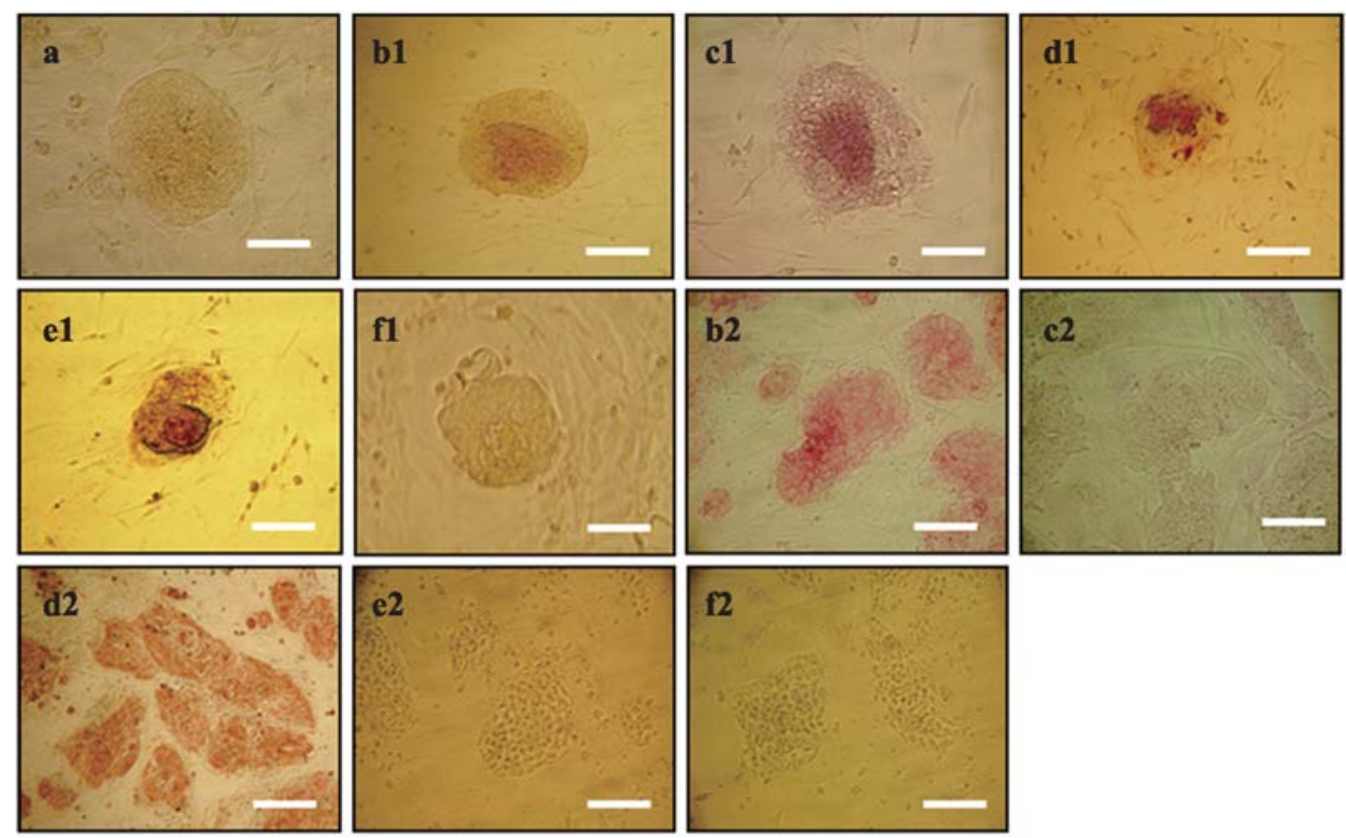

(g)

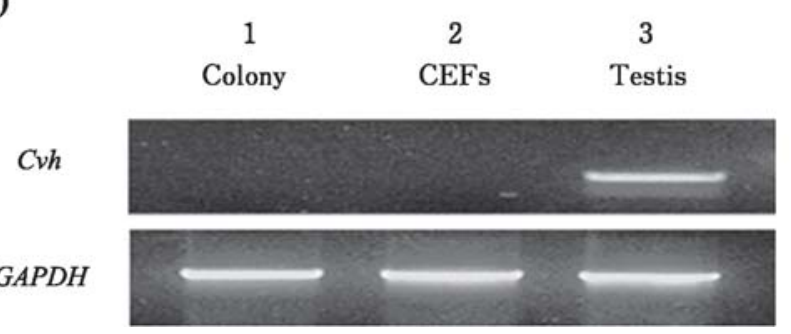

Fig. 4. Characterization of cell aggregates derived from culture of chicken embryonic fibroblasts (CEFs). White leghorn CEFs collected from 8-day-old embryos were cultured for 5 days in the medium supplemented with $1 \mathrm{mM}$ glutathione and the cell aggregates (a) retrieved at the end of primary culture were characterized by staining with alkaline phosphatase (AP; b1), periodic acid Schiff solution (PAS; c1), anti-stage specific embryonic antigen (SSEA)-1 (d1), anti-SSEA-3 (e1) and antiSSEA-4 (f1) antibodies. As the positive control, mouse E14 embryonic stem cells (ESCs) were also characterized as the control treatment (b2f2). Cell aggregates were positive for PAS, and anti-SSEA-1 and antiSSEA-3 antibodies, while negative for AP and anti-SSEA-4 antibody. In contrast, E14 ESCs were positive for AP (b2) and anti-SSEA-1 antibody (d2), but negative for PAS (c2), and anti-SSEA-3 (e2) and anti-SSEA-4 (f2) antibodies. Expression of germ cell-specific chicken vasa homolog $(C v h)$ in the cell aggregates were monitored by RT-PCR $(\mathrm{g}) ; C v h$ levels of the cell aggregates (line 1), non-colonized embryonic fibroblasts (line 2 ) and testicular tissue as a control treatment. There was no $C v h$ expression in colonized and non-colonized embryonic fibroblasts, while strong expression was detected in the testicular tissue. Scale bar $=50 \mu \mathrm{m}$. 

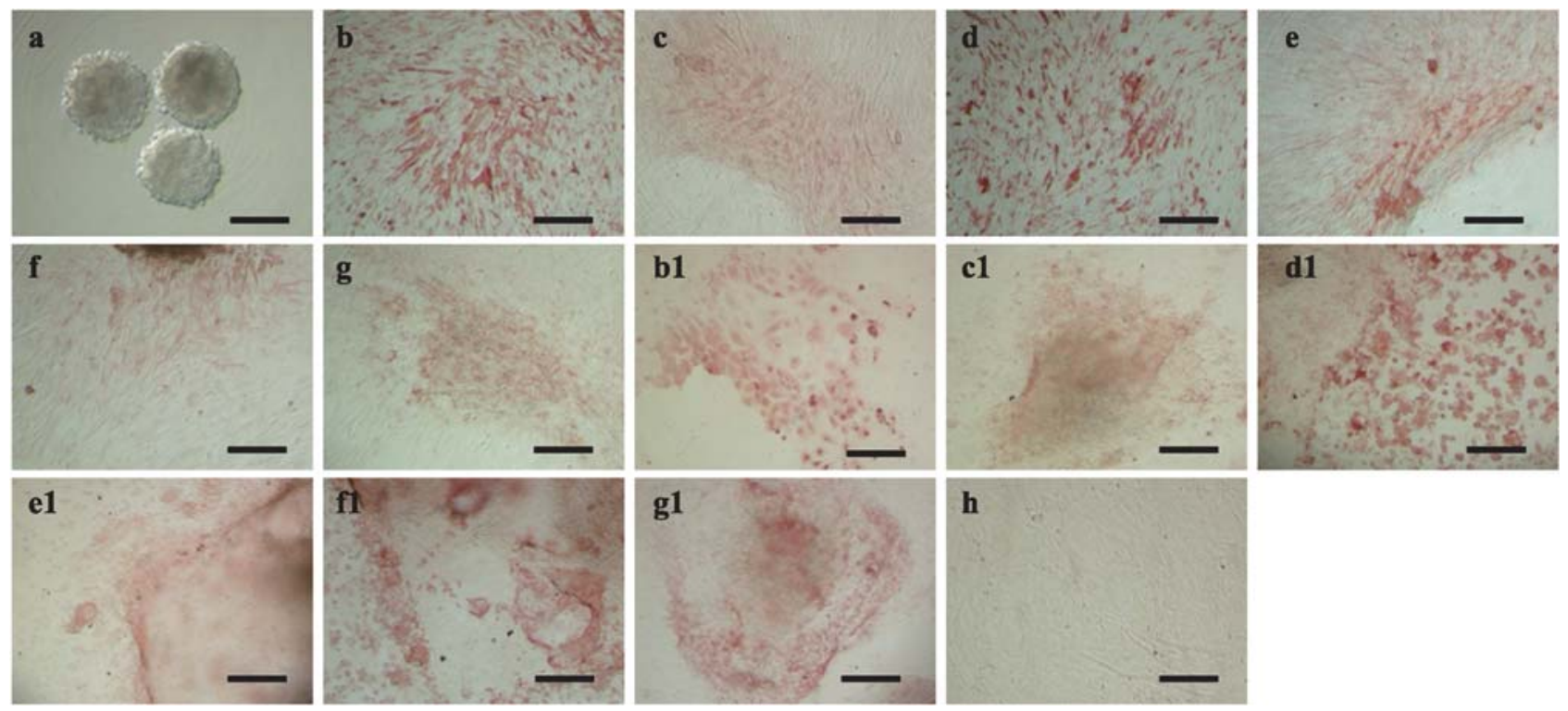

Fig. 5. In vitro differentiation of cell aggregates derived from chicken embryonic fibroblasts (CEFs) into embryoid bodies (EBs) by culturing in leukemia inhibitory factor-free culture medium. (a) EBs observed on day 4 of culture. Immunocytochemical analysis of putative EBs using germinal layer-specific S-100 (b; ectodermal), Nestin (c; ectodermal), smooth muscle actin (d; mesodermal), desmin (e; mesodermal), $\alpha$-fetoprotein (f; endodermal) and Troma-1 (g; endodermal). Mouse E14 embryonic stem cells (ESCs) were concomitantly stained as the control treatment (b1-g1). Differentiated cells were stained without primary antibody as a negative control (h). Strong reactivity was detected after staining with three germ layer-specific markers. Scale bar= $100 \mu \mathrm{m}$.

found a strong evidence to derive stem cells from the culture of non-germline fibroblasts. In addition to our effort on developing an effective subculture system of the colonyforming cells, we are endeavoring on characterizing of the established cells more in details. All of our efforts contribute to developing avian biotechnology for bioreactor production and model development.

\section{Acknowledgments}

This work was supported by Basic Science Research Program (2010-0013172), by WCU programs (R31-10056) and by Priority Research Centers Program (2009-0093820) through the National Research Foundation of Korea (NRF) funded by the Ministry of Education, Science and Technology.

\section{References}

Gong SP, Lee ST, Lee EJ, Kim DY, Lee G, Chi SG, Ryu BK, Lee $\mathrm{CH}$, Yum KE, Han JY, Tilly JL and Lim JM. Embryonic stem cell-like cells established by culture of adult ovarian cells. Fertility Sterility, 93: 2594-2601. 2010.

Horiuchi H, Tategaki A, Yamashita Y, Hisamatsu H, Ogawa M, Noguchi T, Aosasa M, Kawashima T, Akita S, Nishimichi N, Mitsui N, Furusawa S and Matsuda H. Chicken leukemia inhibitory factor maintains chicken embryonic stem cells in the undifferentiated state. Jourmal Biological Chemistry, 279: 24514-24520. 2004.

Jung JG, Lee YM, Park TS, Park SH, Lim JM and Han JY. Identification, Culture, and Characterization of Germline Stem Cell-Like Cells in Chicken Testes. Biology of Reproduction, 76: 173-182. 2007.

Kang SJ, Choi JW, Kim SY, Park KJ, Kim TM, Lee YM, Kim H, Lim JM and Han JY. Reproduction of wild birds via interspecies germ cell transplantation. Biology of Reproduction, 79: 931-937. 2008.

Kim JN, Park TS, Park SH, Park KJ, Kim TM, Lee SK, Lim JM and Han JY. Migration and proliferation of intact and genetically modified primordial germ cells and the generation of a transgenic chicken. Biology of Reproduction, 82: 257-62. 2010.

Kim MA, Park TS, Kim JN, Park HJ, Lee YM, Ono T, Lim JM and Han JY. Production of quail (Cotumix japonica) germline chimeras by transfer of gonadal primordial germ cell into recipient embryo. Theriogenology, 63: 774-782. 2005.

Kues WA, Anger M, Carnwath JW, Paul D, Motlik J and Niemann H. Cell cycle synchronization of porcine fetal fibroblasts: Effects of serum deprivation and reversible cell cycle inhibitors. Biology of Reproduction, 62: 412-419. 2000.

Moulin VD, Garrel, FA, O'Connor-McCourt AM, Castilloux G and Germain L. What's new in human wound-healing myofibroblasts. Current topics in pathology. Ergebnisse der Pathologie, 
93: 123-133. 1999.

Naito M, Tajima A, Yasuda Y and Kuwana T. Production of germline chimeric chickens, with high transmission rate of donorderived gametes, produced by transfer of primordial germ cells. Molecular Reproduction and Development, 39: 153-161. 1994.

Okita K, Ichisaka T and Yamanaka S. Generation of germlinecompetent induced pluripotent stem cells. Nature, 448: 313317. 2007.

Ono T, Matsumoto T and Arisawa Y. Production of donor-derived offspring by transfer of primordial germ cells in Japanese quail. Experimental Animals, 47: 215-219. 1998.

Park TS, Hong YH, Kwon SC, Lim JM and Han JY. Birth of germline chimeras by transfer of chicken embryonic germ (EG) cells into recipient embryos. Molecular Reproduction and Development, 65: 389-395. 2003.

Park TS, Jeong DK, Kim JN, Song GH, Hong YH, Lim JM and Han JY. Improved germline transmission in chicken chimeras produced by transplantation of gonadal primordial germ cells into recipient embryos. Biology of Reproduction, 68: 16571662. 2003.

Petitte JN, Liu G and Yang Z. Avian pluripotent stem cells. Mechanisms of Development, 121: 1159-1168. 2004.

Reynes J, Mallie M, Ravisse P and Bastide JM. Activity of fluconazole against Candida albicans isolates from $\mathrm{HIV}+$ pa- tients in a digestive candidosis turkey model. Journal of Medical and Veterinary Mycology, 30: 363-367. 1992.

Shin SS, Kim TM, Kim SY, Kim TW, Seo HW, Lee SK, Kwon SC, Lee GS, Kim H, Lim JM and Han HY. Generation of transgenic quails through germ cell-mediated germline transmission. Official publication of the Federation of American Societies for Experimental Biology, 22: 2435-2444. 2008.

Takahashi K and Yamanaka S. Induction of pluripotent stem cells from mouse embryonic and adult fibroblast cultures by defined factors. Cell, 126: 663-676. 2006.

Van de Lavoir MC, Diamond JH, Leighton PA, Mather-Love C, Heyer BS, Bradshaw R, Kerchner A, Hooi LT, Gessaro TM, Swanberg SE, Delany ME and Etches RJ. Germline transmission of genetically modified primordial germ cells. Nature Biotechnology, 24: 955-956. 2006.

Wang YC, Brooks F, Jones SA, Olliff LK, Morgan M, Specksnijder GL, Foley C and Harvey AJ. Progress toward the culture and transformation of chicken blastodermal cells. Stem Cells, 24: 1638-1645. 2006.

Yamamoto Y, Usui F, Nakamura Y, Ito Y, Tagami T, Nirasawa K, Matsubara Y, Ono T and Kagami H. A novel method to isolate primordial germ cells and its use for the generation of germline chimeras in chicken. Biology of Reproduction, 77: 115-119. 2007. 